\title{
Special Environments: Altitude and Heat
}

\author{
Philo U. Saunders \\ Australian Institute of Sport and University of Canberra \\ Laura A. Garvican-Lewis \\ Australian Institute of Sport and Australian Catholic University \\ Robert F. Chapman \\ Indiana University \\ Julien D. Périard \\ University of Canberra
}

\begin{abstract}
High-level athletes are always looking at ways to maximize training adaptations for competition performance, and using altered environmental conditions to achieve this outcome has become increasingly popular by elite athletes. Furthermore, a series of potential nutrition and hydration interventions may also optimize the adaptation to altered environments. Altitude training was first used to prepare for competition at altitude, and it still is today; however, more often now, elite athletes embark on a series of altitude training camps to try to improve sea-level performance. Similarly, the use of heat acclimation/acclimatization to optimize performance in hot/humid environmental conditions is a common practice by high-level athletes and is well supported in the scientific literature. More recently, the use of heat training to improve exercise capacity in temperate environments has been investigated and appears to have positive outcomes. This consensus statement will detail the use of both heat and altitude training interventions to optimize performance capacities in elite athletes in both normal environmental conditions and extreme conditions (hot and/or high), with a focus on the importance of nutritional strategies required in these extreme environmental conditions to maximize adaptations conducive to competitive performance enhancement.
\end{abstract}

Keywords: acclimatization, athletes, performance, training

Athletes in the sport of track and field are often faced with training or competing in challenging environmental conditions. The 2019 IAAF World Athletics Championships (Doha, Qatar) and the 2020 Olympic Games (Tokyo, Japan) are anticipated to have the highest heat index in the history of those respective events. The IAAF World Cross Country Championships in 2015 (Guiyang, China; elevation 1,275 m) and 2017 (Kampala, Uganda; elevation $1,210 \mathrm{~m}$ ) were held at altitudes high enough to significantly impair aerobic performance. In the consensus statement, we will briefly discuss the physiological effects that the environments of heat/ humidity and altitude have on track-and-field performance and how athletes and coaches can utilize altered environmental conditions to acclimatize and best prepare. With that background in hand, we will share recommendations on specific nutritional interventions that can be utilized to help optimize performance (both in training

Saunders and Garvican-Lewis are with Performance Services, Australian Institute of Sport, Canberra, Australian Capital Territory, Australia. Saunders and Périard are with the University of Canberra Research Institute for Sport and Exercise (UCRISE), University of Canberra, Canberra, Australian Capital Territory, Australia. Garvican-Lewis is also with the Mary MacKillop Institute for Health Research, Australian Catholic University, Melbourne, Victoria, Australia. Chapman is with Human Performance Laboratory, Department of Kinesiology, Indiana University, Bloomington, IN, USA. Saunders (philo.saunders@ausport.gov.au) is the corresponding author. and competition) in the adverse environmental conditions of thermal load and altitude.

\section{Heat Acclimation/Acclimatization for Competition in the Heat}

Acute exposure to hot and/or humid ambient conditions is well known to result in the development of thermal strain (i.e., elevated skin, muscle, and core temperatures) during prolonged exercise and, consequently, impair aerobic performance (Gonzalez-Alonso et al., 1999; Périard \& Racinais, 2016). This impairment is linked to a thermoregulatory-mediated rise in circulatory and cardiovascular strain that decreases maximal aerobic capacity $\left(\mathrm{VO}_{2} \max\right.$; Ely et al., 2010; Périard \& Racinais, 2015; Périard et al., 2011) and a potential hyperthermia-induced reduction in voluntary drive (i.e., motivation; Febbraio et al., 1994, 1996). Heat stress exercise also leads to a greater reliance on muscle glycogen and anaerobic metabolism (Febbraio et al., 1994, 1996), which may deplete endogenous stores of glycogen. Along with influencing performance, the development of hyperthermia increases the risk of experiencing exertional heat illness, which is a serious health hazard leading to more deaths than all other natural disasters combined (Leon \& Bouchama, 2015). Notwithstanding, when repeatedly exposed to conditions that elicit profuse sweating and elevate whole-body temperature, adaptations 
develop that reduce the deleterious effects of heat stress. Heat acclimation and acclimatization, which refer to periods of heat exposure undertaken in artificial (laboratory) or natural (outdoor) settings, respectively, lead to improved submaximal exercise performance, increased $\mathrm{VO}_{2} \mathrm{max}$, and improved thermal comfort in the heat (Periard et al., 2015; Sawka et al., 2011). These benefits are achieved through enhanced sweating and skin blood flow responses, plasma volume expansion, better fluid balance (hydration), and cardiovascular stability, as well as acquired thermal tolerance (Periard et al., 2016; Tyler et al., 2016).

Adaptations to the heat are generally achieved through four broad induction pathways: (a) constant work rate exercise, (b) selfpaced exercise, (c) controlled hyperthermia or isothermic heat acclimation, and (d) controlled heart rate (relative intensity) heat acclimation (Daanen et al., 2018). While these approaches all have merit and induce heat adaptations, exercise-heat acclimatization has been purported to provide more specific responses due to exposure to the exact conditions that will be encountered during training or competition (i.e., exercise task, solar radiation, wind speed, and terrain/geography; Periard et al., 2015). The time course of heat acclimation/acclimatization has been demonstrated to be relatively rapid, with a significant fraction of the adaptations developing during the first week of heat exposure, and 10-14 days being optimal for complete or near-complete acclimation/ acclimatization (Periard et al., 2015, 2016; Tyler et al., 2016).

Interestingly, the rate of decay for the main adaptive benefits (i.e., lowered heart rate and core temperature during exercise) is 2.5\% per day without heat exposure (Daanen et al., 2018). As such, athletes tapering for a major race after a heat acclimation/acclimatization regimen may lose $35 \%$ of their adaptations after 2 weeks without heat exposure. Training regularly has been suggested to aid in maintaining adaptation, however, as athletes can achieve high core temperatures and sweat rates when training vigorously, even in cooler climates. Therefore, it is recommended to complete an acclimatization regimen as close as possible to the competition being held in the heat.

\section{Heat Training for Improved Performance in Temperate Conditions}

In recent years, there has been a noticeable shift in trying to use heat acclimation to provide an added benefit to performance in cool conditions. There have been reported improvements in $\mathrm{VO}_{2} \mathrm{max}$ in untrained $(13 \%)$ and unfit $(23 \%)$ individuals in cool conditions after 8 days of working in the heat (Shvartz et al., 1977) and an increase $(32 \%)$ in running time to exhaustion following postexercise sauna bathing (Scoon et al., 2007); although others have reported no improvements (Keiser et al., 2015) or inconclusive findings (Neal et al., 2016a).

The mechanisms modulating the potential transfer of adaptations and performance improvements between hot and cool conditions remain unresolved, but could be linked to a variety of ergogenic responses, such as cardiovascular, thermoregulatory, and cellular adaptations. For example, an increase in plasma volume resulting from chronic bouts of exercise in the heat may decrease whole blood viscosity, which has been shown to have positive effects on endurance performance (Telford et al., 1994). Adaptations from training in hot conditions may also allow athletes to train at any given speed with a lower heart rate and core body temperature, both factors being associated with improved exercise economy (Thomas et al., 1995). This is supported by findings from
Lorenzo et al. (2010) of increased performance in a cool environment following heat acclimation being associated with improved economy, lactate threshold, and cardiac performance. Accordingly, heat acclimation may provide a stimulus for enhancing performance in nonthermally challenging environments by improving $\mathrm{VO}_{2}$ max, lactate threshold, and exercise economy (Corbett et al., 2014). It has also been suggested that heat acclimation may preserve or enhance performance at altitude (White et al., 2014). The purported pathways for such a response include plasma volume expansion and improved cardiac efficiency, and involve the upregulation of hypoxia-inducible factor- 1 in boosting oxygen delivery. Additional research is required, however, to thoroughly elucidate the mechanisms associated with improvements in performance in cool conditions and at altitude, as well as to fully substantiate the ergogenic cross-benefits of heat training on performance in these environments (Lee et al., 2016; McCleave et al., 2017; White et al., 2016).

\section{Periodization of Heat Training Within a Season}

A key question for elite athletes regarding the implementation of heat training is when to schedule it in the overall training program and, in particular, ahead of competing in the heat. Prior to a major competition, most athletes will undertake a block of training in which the volume and/or intensity are increased, followed by a period of taper. It has been suggested that a 1- to 2-week heat acclimation regimen with the controlled heart rate approach (Periard et al., 2015) can be used as part of the training program 4-6 weeks prior to competition, providing a constant stimulus for adaptation and minimally affecting regular training. This could then be supplemented with regular passive heat exposure during the weeks prior to competition, or a short (2-4 days) reacclimation period the week before competition (Figure 1). This is suggested because a reacclimation regimen, when undertaken within a month of the original acclimation protocol, leads to a faster (re)induction of adaptations (Daanen et al., 2018).

While exercise-heat exposure during the taper may help maintain the benefits of heat acclimation, it may also interfere with the goal to reduce the overall training load. Passive heat exposure (e.g., sauna or hot bath) following a training session in a cool climate (Stanley et al., 2015; Zurawlew et al., 2016) may thus be preferred during the taper. Given the risk of losing some of the exercise adaptations, maintaining some "easy" exercise sessions in the heat during the taper period may help to better maintain adaptations prior to competing in the heat. Figure 1 summarizes some of the different approaches that can be adopted in preparing for competition in the heat based on available time, resources, and arrival at the competition venue.

\section{Nutrition for Training in the Heat}

Carbohydrate requirements for exercise are increased in the heat due to a shift in substrate utilization toward carbohydrate oxidation (Febbraio, 2001). Daily food patterns should focus on replacing glycogen stores after exercise. Competition strategies should include activities to enhance carbohydrate availability, such as building up glycogen stores in preparation for endurance events, pre-event carbohydrate intake, and intake of glucose/electrolytes in events lasting longer than $60 \mathrm{~min}$. This can be done using water and the carbohydrate gel preparations or using sports drinks. It has been 

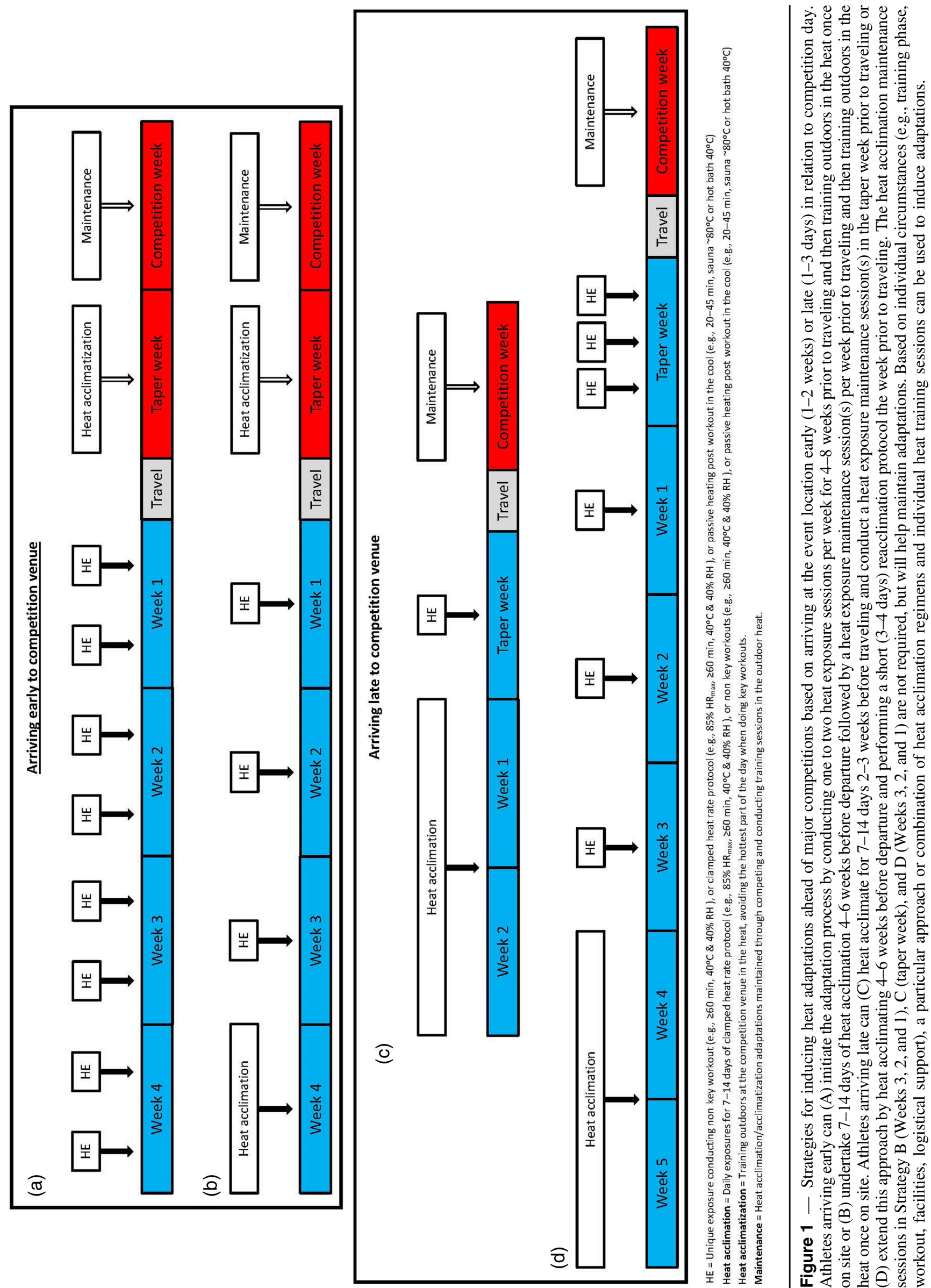
reported that an intake of carbohydrates prior to and during prolonged exercise in the heat provides benefits to exercise performance (Burke et al., 2005).

Hydration in hot/humid conditions is critical to maximize performance during training and competition. Athletes should, therefore, undertake endurance events in a rested, well-fed, and well-hydrated state (Racinais et al., 2015). They may, thus, consume 5-6 $\mathrm{ml}$ of water per kilogram of body mass every $2-3 \mathrm{hr}$ prior to training or competing in the heat, having tested this strategy prior to racing in a major competition to establish volume needs. During exercise, it is advisable to minimize body mass losses induced via sweating, while using caution to avoid overdrinking. Those who sweat profusely may require supplementing their fluids with additional sodium (e.g., $3.0 \mathrm{~g}$ of salt added to $0.5 \mathrm{~L}$ of a carbohydrate-electrolyte solution). From a practical perspective, it was recently highlighted that high-intensity exercise in which sweat rate is elevated, along with activities lasting $>90 \mathrm{~min}$ in the heat, should be accompanied with a planned hydration strategy (Kenefick, 2018). In contrast, drinking to thirst may be sufficient to offset fluid losses during low-intensity exercise of shorter duration (<90 min) in cool climates. Recovery of significant fluid loss after exercise is assisted by the simultaneous replacement of electrolyte loss. Sports drinks (e.g., flavored drinks consisting of water, some salt, and sugar) allow more complete hydration than drinking plain water or soft drinks because they have optimal sugar concentrations to maximize the uptake of water by the body. Consuming a combination of fluids and solid foods is also advisable for rehydration and electrolyte replacement.

The notion that permissive dehydration or restricted fluid consumption may enhance the adaptive response (e.g., plasma volume expansion) during chronic heat exposure has recently been explored. Although pathway(s) via which this might be achieved have been proposed (i.e., increased fluid regulatory, thermal, and cardiovascular strain), contention currently exists regarding the efficacy of this approach (Garrett et al., 2014; Neal et al., 2016b; Pethick et al., 2019). Additional studies are, therefore, warranted to fully elicit whether this practice is efficacious at enhancing adaptation or potentially deleterious in optimizing performance gains through compromised heat training sessions (i.e., lower workloads). Further examination is also required as to whether protein and carbohydrate supplementation during heat acclimation enhances plasma volume expansion by increasing plasma albumin content, leading to enhanced thermoregulatory responses and attenuated cardiovascular strain (Goto et al., 2010).

\section{Altitude Training for Improved Training and Competition in Normoxia}

\section{Adaptation to Altitude}

Physiologically, endurance exercise performance at altitude is primarily affected by a reduction in oxygen delivery to the musculature (Chapman, 2013). Within minutes of exposure to altitude, the elegant design of the human body induces acclimatization responses that are largely dependent on the severity and duration of the altitude exposure (Fulco et al., 1998), as well as individual response characteristics (Chapman et al., 1998). Adaptation to a hypoxic environment results in a variety of physiological responses that have the potential to increase endurance performance at sea level (Saunders et al., 2009a). While an altitude-induced acceleration of red blood cell production resulting in an increase in total hemoglobin mass $\left(\mathrm{Hb}_{\text {mass }}\right)$ is often considered the primary mechanism by which altitude training improves endurance performance (Levine \& StrayGundersen, 2005), a number of nonhematological adaptations may be equally as important (Gore et al., 2007), including improved running economy (Saunders et al., 2004, 2009c) and buffering capacity (Gore et al., 2001). Thus, understanding the timing of peak performance following altitude training is increasingly difficult, given the expected differences in the time course of decay for each adaptation.

\section{Altitude Training Modalities}

Altitude training, in various forms, has grown in popularity since the 1968 Olympic Games were held in Mexico City at $>2,000 \mathrm{~m}$, so much so that elite endurance athletes who choose not to use some form of altitude training within their preparation are often in the minority among the athletic community. With growing advances in technology, so too are the options for incorporating various modalities of altitude training into the training plan, even for sea-level dwellers including altitude chambers and altitude tents for passive and active exposure to altitude. While the efficacy of altitude training for improved performance at sea level is still debated among the scientific community (Lundby \& Robach, 2016; Millet et al., 2017), much of the attention now has turned to the optimization of each method.

Traditional altitude training methods (classical/traditional/live high:train high [LHTH]), born out of the routine practice of altitude natives, involve living and training continuously at natural altitudes usually between 1,500 and 3,000 m (Friedmann-Bette, 2008; Saunders et al., 2009a). Often termed $L H T H$, natural altitude training camps can range from 2 to 6 weeks and are often repeated multiple times throughout a year. The ideal elevation depends greatly upon the logistics and facilities associated with each location, but recent research suggests that 2,000-2,200 m provides an optimal balance between the hypoxic dose (Garvican-Lewis et al., 2016b) and training quality (Sharma et al., 2017). Traditional altitude training remains a staple in the endurance athlete's training preparation, and the current scientific literature supports anecdotal claims of improved sea-level performance (Bonetti \& Hopkins, 2009).

Live high:train low was popularized in the 1990s, and it combines sleeping at altitude with training conducted either at sea level or substantially lower altitudes (Levine \& Stray-Gundersen, 1997). The purported benefits of LHTL are that the hypoxic dose (and thus associated adaptations) can be maximized without compromising training quality (Levine \& Stray-Gundersen, 1997). LHTL can be achieved either using suitable natural altitude training locations that allow relatively easy access to lower level training locations or, more commonly, using simulated altitude chambers or tents. Simulated altitude can be achieved via nitrogen dilution or oxygen filtration and presents a viable option for athletes from countries lacking suitable terrestrial training locations. The total hypoxic dose is an important consideration for those engaging in LHTL, since daily exposure is less than for those engaging in LHTH. Typically, 3-4 weeks at a simulated altitude of 3,000 m, averaging 14 hr of exposure per day, is recommended (Clark et al., 2009), equating to a total hypoxic dose of $882-1,176 \mathrm{~km} \cdot \mathrm{hr}$ (Garvican-Lewis et al., 2016b).

\section{Altitude Training for Competition at Altitude}

In track-and-field endurance events (e.g., marathon and race walking), it is well established that performance at altitude is impaired. For the athlete, coach, or clinician, there are established and 
emerging evidence-based outcomes regarding practical implementation procedures that can help mitigate (but not wholly eliminate) the decline in performance when competing at altitude. First, a general understanding of the specific acclimatization effects that occur with altitude exposure, as well as the timing of those adaptations, allows for proper interventions to maximize positive adaptations and avoid negative ones. Second, there are a number of logistical planning choices under the control of the athlete/coach/ clinician, each of which can strongly affect performance at altitude with both acute and chronic exposure.

\section{Acclimatization Responses With Altitude Exposure}

Interestingly, for performance at altitude following relatively short durations $(<72 \mathrm{hr})$ of exposure to altitude, the well-known acclimatization response of an acute increase in erythropoietin has little influence (Lundby \& Damsgaard, 2006); however, longer term effects of an increase in total $\mathrm{Hb}_{\text {mass }}$ appear to mitigate the $\mathrm{VO}_{2} \mathrm{max}$ decrement with acute exposure to low and moderate altitudes (Robach et al., 2008). Generally, the higher an athlete resides, the greater the magnitude of the physiological altitude acclimatization response (Fulco et al., 1998); however, simply living at a higher altitude does not appear to acutely accelerate the process of altitude acclimatization and actually causes greater performance impairment in the first few days at altitude (Chapman et al., 2016).

\section{Periodization of Altitude Training Within a Season}

When determining when to use altitude training in a yearly plan, there are a number of factors to consider. The severity of altitude, time spent training at altitude, history of altitude training, timing of training leading into competition, whether there is a lower altitude training option, and the type of altitude used are all important factors to consider to maximize the benefits of altitude training.

For elite endurance athletes, altitudes of 1,800-2,500 m are considered optimal for classical altitude training (Saunders et al., 2009a). Altitudes much lower than this do not appear to provide sufficient hypoxic stimulus for key physiological adaptation, although increases in $\mathrm{Hb}_{\text {mass }}$ have been reported from training as low as 1,600 $\mathrm{m}$ (Sharma et al., 2019) and 1,800 m (GarvicanLewis et al., 2015). Altitudes much higher than 2,500 $\mathrm{m}$ have greater potential to cause overtraining and compromise the ability of an athlete to absorb and respond to the hypoxic and training stimuli (Saunders et al., 2009a).

The time spent at altitude is an important factor, as there is no point making the effort to travel and train at altitude if the length of exposure is insufficient to stimulate worthwhile adaptations. It has been recommended to go for 3-4 weeks when using altitude training to improve sea-level performance (Rusko et al., 2004). Recently, a new metric for the hypoxic dose was proposed whereby the total hypoxic dose (in $\mathrm{km} \cdot \mathrm{hr}$ ) is calculated as the elevation (m)/ hours of exposure $\times 1,000$ (Garvican-Lewis et al., 2016b), with the minimum threshold for $\mathrm{Hb}_{\text {mass }}$ adaptation appearing to be $\sim 500 \mathrm{~km} \cdot \mathrm{hr}$. However, the optimal dose for nonhematological benefits associated with altitude, as well as any potential additive effects of several hypoxic exposures within a season, requires further investigation. It is recommended that athletes based at sea level spend no more than 2 months at altitude at any one time and that it is more beneficial for athletes to undertake short blocks (2-6 weeks) more frequently throughout the year, with two to three stints being optimal.
It has been suggested that longer than 8 weeks is required between altitude training stints to maximize the training afterward (Robertson et al., 2010). A longer time between altitude exposures also ensures that athletes are not excessively fatigued going into a subsequent altitude training camp, training phase, or competition. There is also a belief that every subsequent camp at altitude has some form of memory, with training seemingly easier each time an athlete undertakes a training camp at altitude, and potentially, adaptations are better when using altitude repeatedly. As an example, $\mathrm{Hb}_{\text {mass }}$ was measured in elite swimmers over a 4-year period with multiple altitude camps during this period; all swimmers had a linear increase in $\mathrm{Hb}_{\text {mass }}$, with the resultant increase from the end to the start $\sim 10 \%$ (Figure 2). Further work in this area is required to gain some grounded evidence in the area of multiple altitude exposures.

The periodization of the training year and the training phase prior to an altitude camp are other factors that should be considered. The emphasis of training can be tailored to meet the demands of the training phase of the athletes. For example, in the early build-up period, where athletes are trying to increase the volume of training and high-quality training is not as critical, a longer period of altitude training can be undertaken where the focus is on accumulating a high volume of training utilizing the hypoxic stimulus, rather than performing high-intensity training. Low- to moderate-altitude training during a competitive season has been used in elite middledistance runners (Saunders et al., 2009b). In this particular study, seven runners lived at $\sim 1,800 \mathrm{~m}$ and did all their low- to moderateintensity running at 1,700-2,200 m. However, because the athletes were in their competitive season, they completed all high-quality sessions at 900-m altitude to maintain the 800/1,500-m race-pace interval training required to stay race fit. This protocol resulted in an improved competitive performance by $\sim 2 \%$ (Saunders et al., 2009b).

The additional "load" imposed by training at altitude (LHTH) should not be forgotten when designing an altitude training program. While elite athletes with prior altitude experience are likely to handle a normal volume and intensity of training, dramatic increases in overall load are not recommended (Saunders et al., 2009a). To avoid a reduction in race-specific fitness, athletes should undertake a series of shorter race-pace efforts where velocity is not compromised or possibly enhanced due to the reduced air density (Peronnet et al., 1991) and have longer recoveries than at sea level to maintain speed during the entire training session. From experience, at an altitude of $\sim 2,000 \mathrm{~m}$, the maximal interval distance that can be performed at middle distance $(800-1,500 \mathrm{~m}$ ) race pace is $\sim 600 \mathrm{~m}$, and recovery times probably need to be multiplied by $1.5-2.0$ when compared with the same interval sessions performed at sea level. With acclimatization and partial restoration of $\mathrm{VO}_{2}$ max at altitude, the duration of the interval efforts can be increased and/or the recovery times decreased. Recent work has demonstrated that running speed during threshold and $\mathrm{VO}_{2} \max$ intensity training sessions are adversely affected at 2,100-m altitude by $6 \%$ and $4 \%$, respectively, equating to 13 and $6 \mathrm{~s} / \mathrm{km}$ at the speeds at which elite middledistance runners train (Sharma et al., 2017). These findings indicate that descending to a lower altitude (if possible) is beneficial for threshold and $\mathrm{VO}_{2}$ max sessions in order to maximize the $\mathrm{O}_{2}$ flux.

With regard to LHTL altitude exposure, even though the ability to train at or near sea level allows athletes to maintain a higher level of training, the extra stress of living at moderate altitude for most of the day makes training harder and the athletes generally more tired during the LHTL stint. For athletes spending 3 weeks of $14 \mathrm{hr} /$ day at $3,000 \mathrm{~m}$, training is generally harder, and 


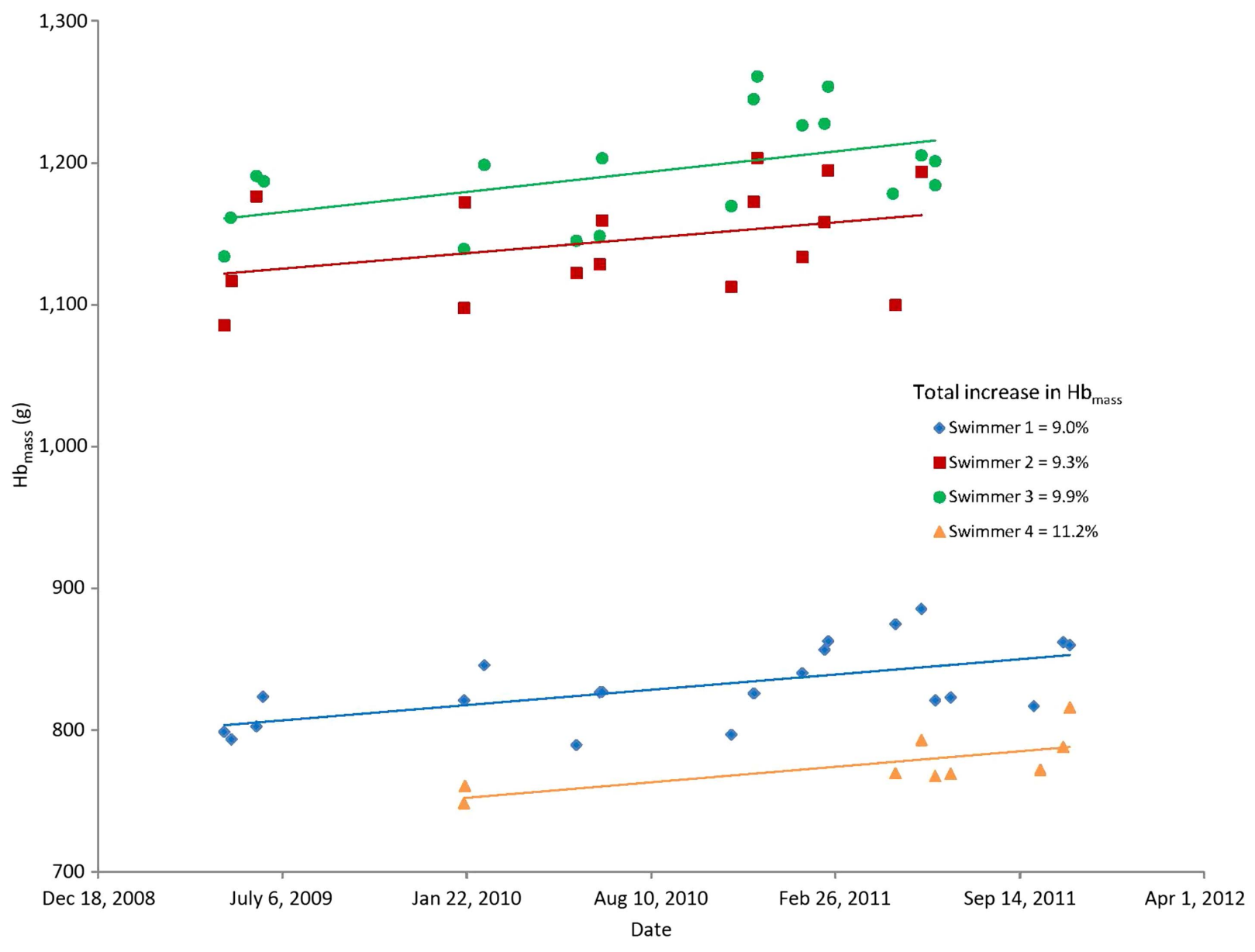

Figure 2 - Progression of $\mathrm{Hb}_{\text {mass }}$ in four elite Australian swimmers over a 4-year period. All data are absolute $\mathrm{Hb}$ mass in grams over eight altitude camps, including both LHTL in Canberra $(3,000 / 600 \mathrm{~m})$ and LHTH in Sierra Nevada, Spain $(2,300 \mathrm{~m})$. LHTH=live high:train high (natural); $\mathrm{LHTL}=$ live high:train low (natural or simulated); $\mathrm{Hb}_{\text {mass }}=$ hemoglobin mass.

modifications are often required to ensure athletes do not overreach during this period. Optimizing recovery and making some modifications to training intensity during the first half of an LHTL camp are both ways to maximize training quality and minimize fatigue levels during such a camp.

The optimal timing of competition after altitude training has not been fully elucidated. Traditional research has focused on performance immediately following exposure (1-2 days post). Interestingly, despite $\mathrm{Hb}_{\text {mass }}$ returning to baseline levels after 4 weeks at sea level (Prommer et al., 2010), performance improvements following a properly executed altitude training camp have been shown to be preserved (McLean et al., 2013b). These outcomes suggest that, in order to achieve peak performance following an altitude camp, it is important to appropriately modify training in a similar manner to a typical taper. If an athlete is competing in the days immediately following the descent, then the last few days to a week at altitude will need to be lighter in order to allow the athlete to freshen up before the descent. If the competition is delayed, then an appropriate recovery block at sea level is necessary to absorb the training and adaptations induced at altitude. Usually, this is just a few days to get over travel fatigue and the general fatigue from training at altitude. This period after altitude is the best time to get high-quality training (particularly higher intensity training rather than increased volume) done, as athletes can train at a higher level than before because of the increased physiological capacities obtained from altitude training. Many athletes find that, during training in the 4-6 weeks postaltitude, they are able to train at a higher level, leading to improved race performance following this block of training (Chapman et al., 2014). This concept is far from new, as in some of the original works from the 1980s examining the effect of blood doping on endurance exercise performance, maximal oxygen uptake in a group of highly trained distance runners remained significantly improved 16 weeks after an infusion of two units of whole blood (Buick et al., 1980). It is generally understood that the increased over time while in the blood-doped condition may have allowed for other physiological adaptations which maintained performance, despite the normalization of red blood cell mass in a fraction of the 16-week time period (Chapman et al., 2014). This concept is also related to a key premise behind the low-altitude training portion of the LHTL altitude training paradigm. By training at low altitude, the athlete is able to train at faster speeds and achieve a higher $\mathrm{O}_{2}$ flux between the muscle capillary and mitochondria compared with training at higher altitudes (Levine \& Stray-Gundersen, 1997). This higher oxygen flux with low-altitude training is believed to be a primary stimulus behind the improved mean steady-state workload improvement in athletes who live high and train low (Levine \& Stray-Gundersen, 1997). Figure 3 presents how altitude can be structured into a competition year based on the outcome of the camp or multiple camps. 


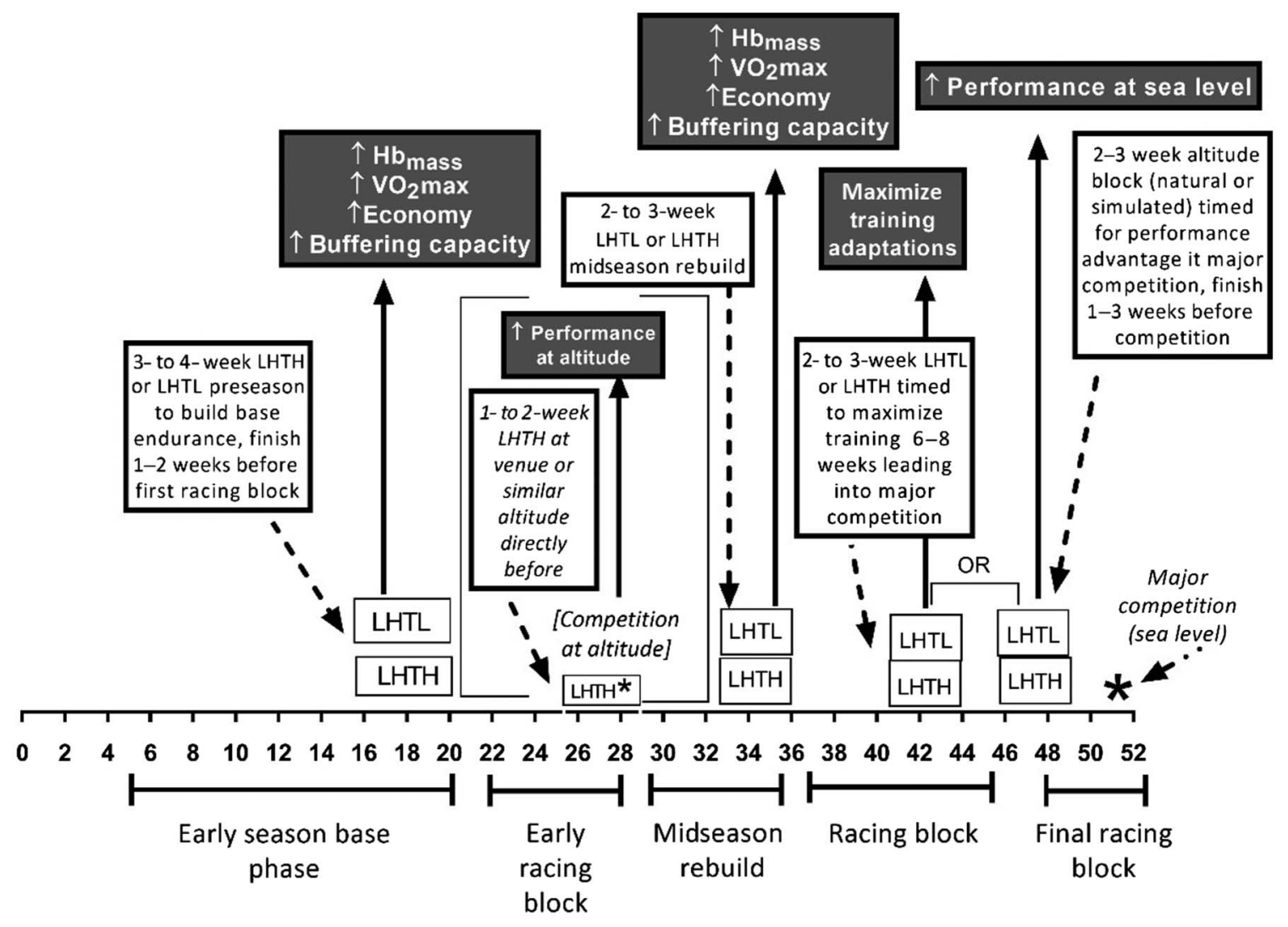

Figure 3 - Sample periodization of altitude training within a season. LHTH = live high:train high (natural); LHTL = live high:train low (natural or simulated). Gray boxes indicate potential outcomes of proposed altitude block, relative to the time in the season. *Recommendation for competition conducted at altitude.

\section{Optimizing Adaption to Altitude}

Athletes can increase the chances of optimal adaptation to altitude by ensuring that a number of appropriate steps (several nutrition based) are taken in the design and implementation of each altitude training camp.

a. Iron: Iron is an essential component of red blood cells and hence iron requirements are increased at altitude. Iron supplementation appears necessary for optimal adaptation (Garvican-Lewis et al., 2016a, 2018), with greater gains in $\mathrm{Hb}_{\text {mass }}$ observed in athletes who were supplemented during exposure compared with those who were not (Govus et al., 2015). Furthermore, a blunted $\mathrm{Hb}_{\text {mass }}$ response was observed in nonsupplemented athletes despite their being iron replete (Garvican-Lewis et al., 2018), providing further support for the notion that iron supplementation during exposure is more important than prealtitude ferritin stores (Garvican-Lewis et al., 2016a). Consequently, following a pre-altitude blood test 1-2 weeks before altitude and medical review, daily oral iron supplementation (50-100 $\mathrm{mg}$ of elemental iron) for the majority of athletes is recommended throughout altitude exposure to support erythropoiesis. Optimization of the dosing strategy employed (e.g., split vs. single doses, or alternate day vs. every day) warrants further investigation in athletic cohorts.

b. Energy intake: A restricted energy intake combined with high training load at altitude (Woods et al., 2017a) has the potential to compromise energy availability, which in turn may inhibit erythropoietic adaptation to altitude, as well as overall health and well-being (Heikura et al., 2018; McLean et al., 2013a). Athletes are advised to maintain a balanced diet and support training with appropriate fuel and fluid intake. Hydration practices should counterbalance the increased fluid loss via ventilation and diuresis, although consumption of large volumes in the evening should be avoided to reduce night waking to pass urine. Macronutrient requirements and overall caloric intake need to be increased at altitude due to a likely increased resting metabolic rate, although it must be noted that further validation is required, since, to date, an increased resting metabolic rate has only been observed in a very small cohort of runners at 2,000 m (Woods et al., 2017b). Furthermore, using altitude as a means to actively decrease body mass in a competition phase is not recommended, since $\mathrm{Hb}_{\text {mass }}$ responses may be compromised (McLean et al., 2013a).

c. Training load/periodization: Particular attention to the training load directly prior to the altitude training block (the "lead-in phase"), training appropriately while at altitude (as detailed in the periodization section above), and commencing an appropriate taper during the final stages of the camp are crucial to successful performance immediately following altitude.

d. Illness/inflammation: Athletes with significant illness or injury appear compromised in their adaptation to altitude 
(Gore et al., 1998; Heikura et al., 2018; Wachsmuth et al., 2013), and therefore, altitude training may need to be delayed or modified if illness and injury is present. Appropriate hygiene practices are strongly recommended during an altitude camp.

\section{Conclusion}

The use of altitude and heat as interventions to prepare for competitions in these conditions is essential and supported by a large body of evidence. Altitude training in particular further provides performance benefits for competition in normal environmental conditions (i.e., sea level), with heat training possibly aiding performance in the cool environment. It seems sensible for coaches and elite athletes, especially on the endurance side of athletics, to investigate the use of altitude and heat training. In recent times, it has been widely discussed whether the concurrent use of heat and altitude enhances the potential adaptations from both training methods and results in even greater performance outcomes than their independent use. Altitude training can provide an increased oxygen-carrying capacity, a more efficient use of oxygen, and a better ability to tolerate anaerobic metabolism; heat training has the ability to increase plasma volume and reduce cardiovascular and thermoregulatory strain. It is recommended to focus on the intervention most relevant to competition and ensure that training, nutrition, and recovery are optimized to allow positive training adaptations and, ultimately, performance enhancement.

\section{References}

Bonetti, D.L., \& Hopkins, W.G. (2009). Sea-level exercise performance following adaptation to hypoxia: A meta-analysis. Sports Medicine, 39(2), 107-127. PubMed ID: 19203133 doi:10.2165/00007256200939020-00002

Buick, F.J., Gledhill, N., Froese, A.B., Spriet, L., \& Meyers, E.C. (1980). Effect of induced erythrocythemia on aerobic work capacity. Journal of Applied Physiology: Respiratory, Environmental and Exercise Physiology, 48(4), 636-642. doi:10.1152/jappl.1980.48.4.636

Burke, L.M., Wood, C., Pyne, D.B., Telford, D.R., \& Saunders, P.U. (2005). Effect of carbohydrate intake on half-marathon performance of well-trained runners. International Journal of Sport Nutrition and Exercise Metabolism, 15(6), 573-589. PubMed ID: 16521844 doi:10. 1123/ijsnem.15.6.573

Chapman, R.F. (2013). The individual response to training and competition at altitude. British Journal of Sports Medicine, 47(Suppl 1), i40-i44. doi:10.1136/bjsports-2013-092837

Chapman, R.F., Karlsen, T., Ge, R.L., Stray-Gundersen, J., \& Levine, B.D. (2016). Living altitude influences endurance exercise performance change over time at altitude. Journal of Applied Physiology, 120(10), 1151-1158. doi:10.1152/japplphysiol.00909.2015

Chapman, R.F., Laymon Stickford, A.S., Lundby, C., \& Levine, B.D. (2014). Timing of return from altitude training for optimal sea level performance. Journal of Applied Physiology, 116(7), 837-843. doi:10.1152/japplphysiol.00663.2013

Chapman, R.F., Stray-Gundersen, J., \& Levine, B.D. (1998). Individual variation in response to altitude training. Journal of Applied Physiology, 85(4), 1448-1456. PubMed ID: 9760340 doi:10.1152/jappl. 1998.85.4.1448

Clark, S.A., Quod, M.J., Clark, M.A., Martin, D.T., Saunders, P.U., \& Gore, C.J. (2009). Time course of haemoglobin mass during 21 days live high:train low simulated altitude. European Journal of Applied
Physiology, 106(3), 399-406. PubMed ID: 19294411 doi:10.1007/ s00421-009-1027-4

Corbett, J., Neal, R.A., Lunt, H.C., \& Tipton, M.J. (2014). Adaptation to heat and exercise performance under cooler conditions: A new hot topic. Sports Medicine, 44(10), 1323-1331. PubMed ID: 24943043 doi:10.1007/s40279-014-0212-8

Daanen, H.A.M., Racinais, S., \& Periard, J.D. (2018). Heat acclimation decay and re-induction: A systematic review and meta-analysis. Sports Medicine, 48(2), 409-430. doi:10.1007/s40279-017-0808-x

Ely, B.R., Cheuvront, S.N., Kenefick, R.W., \& Sawka, M.N. (2010). Aerobic performance is degraded, despite modest hyperthermia, in hot environments. Medicine \& Science in Sports \& Exercise, 42(1), 135-141. PubMed ID: 20010120 doi:10.1249/MSS.0b013e3181adb9fb

Febbraio, M.A. (2001). Alterations in energy metabolism during exercise and heat stress. Sports Medicine, 31(1), 47-59. PubMed ID: 11219501 doi:10.2165/00007256-200131010-00004

Febbraio, M.A., Carey, M.F., Snow, R.J., Stathis, C.G., \& Hargreaves, M. (1996). Influence of elevated muscle temperature on metabolism during intense, dynamic exercise. American Journal of Physiology, 271(5 Pt 2), R1251-R1255. PubMed ID: 8945960

Febbraio, M.A., Snow, R.J., Hargreaves, M., Stathis, C.G., Martin, I.K., \& Carey, M.F. (1994). Muscle metabolism during exercise and heat stress in trained men: Effect of acclimation. Journal of Applied Physiology, 76(2), 589-597. doi:10.1152/jappl.1994.76.2.589

Friedmann-Bette, B. (2008). Classical altitude training. Scandinavian Journal of Medicine \& Science in Sports, 18(Suppl. 1), 11-20. doi:10.1111/j.1600-0838.2008.00828.x

Fulco, C.S., Rock, P.B., \& Cymerman, A. (1998). Maximal and submaximal exercise performance at altitude. Aviation, Space, and Environmental Medicine, 69(8), 793-801. PubMed ID: 9715971

Garrett, A.T., Goosens, N.G., Rehrer, N.J., Patterson, M.J., Harrison, J., Sammut, I., \& Cotter, J.D. (2014). Short-term heat acclimation is effective and may be enhanced rather than impaired by dehydration. American Journal of Human Biology, 26(3), 311-320. PubMed ID: 24469986 doi:10.1002/ajhb.22509

Garvican-Lewis, L.A., Govus, A.D., Peeling, P., Abbiss, C.R., \& Gore, C.J. (2016a). Iron supplementation and altitude: Decision making using a regression tree. Journal of Sports Science and Medicine, 15(1), 204-205.

Garvican-Lewis, L.A., Halliday, I., Abbiss, C.R., Saunders, P.U., \& Gore, C.J. (2015). Altitude exposure at $1800 \mathrm{~m}$ increases haemoglobin mass in distance runners. Journal of Sports Science and Medicine, 14(2), 413-417. PubMed ID: 25983592

Garvican-Lewis, L.A., Sharpe, K., \& Gore, C.J. (2016b). Time for a new metric for hypoxic dose? Journal of Applied Physiology, 121(1), 352-355. doi:10.1152/japplphysiol.00579.2015

Garvican-Lewis, L.A., Vuong, V.L., Govus, A.D., Peeling, P., Jung, G., Nemeth, E., . . Gore, C.J. (2018). Intravenous iron does not augment the hemoglobin mass response to simulated hypoxia. Medicine \& Science in Sports \& Exercise, 50(8), 1669-1678. PubMed ID: 29538179 doi:10.1249/MSS.0000000000001608

Gonzalez-Alonso, J., Teller, C., Andersen, S.L., Jensen, F.B., Hyldig, T., $\&$ Nielsen, B. (1999). Influence of body temperature on the development of fatigue during prolonged exercise in the heat. Journal of Applied Physiology, 86(3), 1032-1039. PubMed ID: 10066720 doi:10.1152/jappl.1999.86.3.1032

Gore, C.J., Clark, S.A., \& Saunders, P.U. (2007). Nonhematological mechanisms of improved sea-level performance after hypoxic exposure. Medicine \& Science in Sports \& Exercise, 39(9), 1600-1609. PubMed ID: 17805094 doi:10.1249/mss.0b013e3180de49d3

Gore, C.J., Hahn, A., Rice, A., Bourdon, P., Lawrence, S., Walsh, C., . . . Gore, C. (1998). Altitude training at 2690m does not increase total 
haemoglobin mass or sea level $\mathrm{VO}_{2 \max }$ in world champion track cyclists. Journal of Science and Medicine in Sport, 1(3), 156-170. PubMed ID: 9783517 doi:10.1016/S1440-2440(98)80011-X

Gore, C.J., Hahn, A.G., Aughey, R.J., Martin, D.T., Ashenden, M.J., Clark, S.A., . . McKenna, M.J. (2001). Live high:train low increases muscle buffer capacity and submaximal cycling efficiency. Acta Physiologica Scandinavica, 173(3), 275-286. PubMed ID: 11736690 doi:10.1046/j.1365-201X.2001.00906.X

Goto, M., Okazaki, K., Kamijo, Y., Ikegawa, S., Masuki, S., Miyagawa, K., \& Nose, H. (2010). Protein and carbohydrate supplementation during 5-day aerobic training enhanced plasma volume expansion and thermoregulatory adaptation in young men. Journal of Applied Physiology, 109(4), 1247-1255. doi:10.1152/japplphysiol.00577. 2010

Govus, A.D., Garvican-Lewis, L.A., Abbiss, C.R., Peeling, P., \& Gore, C.J. (2015). Pre-altitude serum ferritin levels and daily oral iron supplement dose mediate iron parameter and hemoglobin mass responses to altitude exposure. PLOS ONE, 10(8), e0135120. PubMed ID: 26263553 doi:10.1371/journal.pone.0135120

Heikura, I.A., Burke, L.M., Bergland, D., Uusitalo, A.L.T., Mero, A.A., \& Stellingwerff, T. (2018). Impact of energy availability, health, and sex on hemoglobin-mass responses following live-high-train-high altitude training in elite female and male distance athletes. International Journal of Sports Physiology and Performance, 13(8), 1090-1096. PubMed ID: 29431548 doi:10.1123/ijspp.2017-0547

Keiser, S., Fluck, D., Huppin, F., Stravs, A., Hilty, M.P., \& Lundby, C. (2015). Heat training increases exercise capacity in hot but not in temperate conditions: A mechanistic counter-balanced cross-over study. American Journal of Physiology. Heart and Circulatory Physiology, 309(5), H750-H761. PubMed ID: 26150574

Kenefick, R.W. (2018). Drinking strategies: Planned drinking versus drinking to thirst. Sports Medicine, 48(Suppl. 1), 31-37. PubMed ID: 29368181 doi:10.1007/s40279-017-0844-6

Lee, B.J., Miller, A., James, R.S., \& Thake, C.D. (2016). Cross acclimation between heat and hypoxia: Heat acclimation improves cellular tolerance and exercise performance in acute normobaric hypoxia. Frontiers in Physiology, 7, 78. PubMed ID: 27014080

Leon, L.R., \& Bouchama, A. (2015). Heat stroke. Comprehensive Physiology, 5(2), 611-647. PubMed ID: 25880507 doi:10.1002/cphy. c140017

Levine, B.D., \& Stray-Gundersen, J. (1997). "Living high-training low": effect of moderate-altitude acclimatization with low-altitude training on performance. Journal of Applied Physiology, 83(1), 102-112. PubMed ID: 9216951 doi:10.1152/jappl.1997.83.1.102

Levine, B.D., \& Stray-Gundersen, J. (2005). Point: Positive effects of intermittent hypoxia (live high:train low) on exercise performance are mediated primarily by augmented red cell volume. Journal of Applied Physiology, 99(5), 2053-2055. PubMed ID: 16227463 doi:10.1152/ japplphysiol.00877.2005

Lorenzo, S., Halliwill, J.R., Sawka, M.N., \& Minson, C.T. (2010). Heat acclimation improves exercise performance. Journal of Applied Physiology, 109(4), 1140-1147. doi:10.1152/japplphysiol.00495. 2010

Lundby, C., \& Damsgaard, R. (2006). Exercise performance in hypoxia after novel erythropoiesis stimulating protein treatment. Scandinavian Journal of Medicine \& Science in Sports, 16(1), 35-40. PubMed ID: 16430679

Lundby, C., \& Robach, P. (2016). Does 'altitude training' increase exercise performance in elite athletes? Experimental Physiology, 101(7), 783-788. PubMed ID: 27173805 doi:10.1113/EP085579

McCleave, E.L., Slattery, K.M., Duffield, R., Saunders, P.U., Sharma, A.P., Crowcroft, S.J., \& Coutts, A.J. (2017). Temperate performance benefits after heat, but not combined heat and hypoxic training. Medicine \& Science in Sports \& Exercise, 49(3), 509-517. PubMed ID: 27787334 doi:10.1249/MSS.0000000000001138

McLean, B.D., Buttifant, D., Gore, C.J., White, K., \& Kemp, J. (2013a). Year-to-year variability in haemoglobin mass response to two altitude training camps. British Journal of Sports Medicine, 47(Suppl. 1), i51-i58. doi:10.1136/bjsports-2013-092744

McLean, B.D., Buttifant, D., Gore, C.J., White, K., Liess, C., \& Kemp, J. (2013b). Physiological and performance responses to a preseason altitude-training camp in elite team-sport athletes. International Journal of Sports Physiology and Performance, 8(4), 391-399. doi:10.1123/ijspp.8.4.391

Millet, G.P., Chapman, R.F., Girard, O., \& Brocherie, F. (2017). Is live high-train low altitude training relevant for elite athletes? Flawed analysis from inaccurate data. British Journal of Sports Medicine. PubMed ID: 29247024 doi:10.1136/bjsports-2017-098083

Neal, R.A., Corbett, J., Massey, H.C., \& Tipton, M.J. (2016a). Effect of short-term heat acclimation with permissive dehydration on thermoregulation and temperate exercise performance. Scandinavian Journal of Medicine \& Science in Sports, 26(8), 875-884.

Neal, R.A., Massey, H.C., Tipton, M.J., Young, J.S., \& Corbett, J. (2016b). Effect of permissive dehydration on induction and decay of heat acclimation, and temperate exercise performance. Frontiers in Physiology, 7, 564. doi:10.3389/fphys.2016.00564

Périard, J.D., Cramer, M.N., Chapman, P.G., Caillaud, C., \& Thompson, M.W. (2011). Cardiovascular strain impairs prolonged self-paced exercise in the heat. Experimental Physiology, 96(2), 134-144. PubMed ID: 20851861 doi:10.1113/expphysiol.2010.054213

Périard, J.D., \& Racinais, S. (2015). Self-paced exercise in hot and cool conditions is associated with the maintenance of $\% \mathrm{VO}_{2 \text { peak }}$ within a narrow range. Journal of Applied Physiology, 118, 1258-1265. PubMed ID: 25814635 doi:10.1152/japplphysiol.00084.2015

Périard, J.D., \& Racinais, S. (2016). Performance and pacing during cycle exercise in hyperthermic and hypoxic conditions. Medicine \& Science in Sports \& Exercise, 48(5), 845-853. PubMed ID: 26656777 doi:10. 1249/MSS.0000000000000839

Periard, J.D., Racinais, S., \& Sawka, M.N. (2015). Adaptations and mechanisms of human heat acclimation: Applications for competitive athletes and sports. Scandinavian Journal of Medicine \& Science in Sports, 25(Suppl. 1), 20-38.

Periard, J.D., Travers, G.J.S., Racinais, S., \& Sawka, M.N. (2016). Cardiovascular adaptations supporting human exercise-heat acclimation. Autonomic Neuroscience, 196, 52-62. PubMed ID: 26905458 doi:10.1016/j.autneu.2016.02.002

Peronnet, F., Thibault, G., \& Cousineau, D.L. (1991). A theoretical analysis of the effect of altitude on running performance. Journal of Applied Physiology, 70(1), 399-404. PubMed ID: 2010398 doi:10. 1152/jappl.1991.70.1.399

Pethick, W.A., Murray, H.J., McFadyen, P., Brodie, R., Gaul, C.A., \& Stellingwerff, T. (2019). Effects of hydration status during heat acclimation on plasma volume and performance. Scandinavian Journal of Medicine \& Science in Sports, 29(2), 189-199. doi:10.1111/ sms.13319

Prommer, N., Thoma, S., Quecke, L., Gutekunst, T., Volzke, C., Wachsmuth, N., . . . Schmidt, W. (2010). Total hemoglobin mass and blood volume of elite Kenyan runners. Medicine \& Science in Sports \& Exercise, 42(4), 791-797. PubMed ID: 19952848 doi:10. 1249/MSS.0b013e3181badd67

Racinais, S., Alonso, J.M., Coutts, A.J., Flouris, A.D., Girard, O., Gonzalez-Alonso, J., . . . Periard, J.D. (2015). Consensus recommendations on training and competing in the heat. Scandinavian Journal of Medicine \& Science in Sports, 25(Suppl. 1), 6-19. 
Robach, P., Calbet, J.A., Thomsen, J.J., Boushel, R., Mollard, P., Rasmussen, P., \& Lundby, C. (2008). The ergogenic effect of recombinant human erythropoietin on VO2max depends on the severity of arterial hypoxemia. PLoS ONE, 3(8), e2996. PubMed ID: 18714372 doi:10.1371/journal.pone.0002996

Robertson, E.Y., Saunders, P.U., Pyne, D.B., Aughey, R.J., Anson, J.M., \& Gore, C.J. (2010). Reproducibility of performance changes to simulated live high/train low altitude. Medicine \& Science in Sports \& Exercise, 42(2), 394-401. PubMed ID: 19927018 doi:10.1249/MSS. 0b013e3181b34b57

Rusko, H.K., Tikkanen, H.O., \& Peltonen, J.E. (2004). Altitude and endurance training. Journal of Sports Sciences, 22(10), 928-944. PubMed ID: 15768726 doi:10.1080/02640410400005933

Saunders, P.U., Pyne, D.B., \& Gore, C.J. (2009a). Endurance training at altitude. High Altitude Medicine \& Biology, 10(2), 135-148. doi:10. 1089/ham.2008.1092

Saunders, P.U., Telford, R.D., Pyne, D.B., Cunningham, R.B., Gore, C.J., Hahn, A.G., \& Hawley, J.A. (2004). Improved running economy in elite runners after 20 days of simulated moderate-altitude exposure. Journal of Applied Physiology, 96(3), 931-937. PubMed ID: 14607850 doi:10.1152/japplphysiol.00725.2003

Saunders, P.U., Telford, R.D., Pyne, D.B., Gore, C.J., \& Hahn, A.G. (2009b). Improved race performance in elite middle-distance runners after cumulative altitude exposure. International Journal of Sports Physiology and Performance, 4(1), 134-138. doi:10.1123/ijspp.4.1.134

Saunders, P.U., Telford, R.D., Pyne, D.B., Hahn, A.G., \& Gore, C.J. (2009c). Improved running economy and increased hemoglobin mass in elite runners after extended moderate altitude exposure. Journal of Science and Medicine in Sport, 12(1), 67-72. doi:10.1016/j.jsams. 2007.08.014

Sawka, M.N., Leon, L.R., Montain, S.J., \& Sonna, L.A. (2011). Integrated physiological mechanisms of exercise performance, adaptation, and maladaptation to heat stress. Comprehensive Physiology, 1(4), 1883-1928. PubMed ID: 23733692 doi:10.1002/cphy.c100082

Scoon, G.S., Hopkins, W.G., Mayhew, S., \& Cotter, J.D. (2007). Effect of post-exercise sauna bathing on the endurance performance of competitive male runners. Journal of Science and Medicine in Sport, 10(4), 259-262. PubMed ID: 16877041 doi:10.1016/j.jsams.2006. 06.009

Sharma, A.P., Saunders, P.U., Garvican-Lewis, L.A., Clark, B., Stanley, J., Robertson, E.Y., \& Thompson, K.G. (2017). The effect of training at 2100-m altitude on running speed and session rating of perceived exertion at different intensities in elite middle-distance runners. International Journal of Sports Physiology and Performance, 12(Suppl. 2), S2147-S2152. PubMed ID: 27736249 doi:10.1123/ijspp. 2016-0402

Sharma, A.P., Saunders, P.U., Garvican-Lewis, L.A., Clark, B., Welvaert, M., Gore, C.J., \& Thompson, K.G. (2019). Improved performance in national-level runners with increased training load at 1600 and $1800 \mathrm{~m}$.
International Journal of Sports Physiology and Performance, 14(3), 286-295. PubMed ID: 30080440 doi:10.1123/ijspp.2018-0104

Shvartz, E., Shapiro, Y., Magazanik, A., Meroz, A., Birnfeld, H., Mechtinger, A., \& Shibolet, S. (1977). Heat acclimation, physical fitness, and responses to exercise in temperate and hot environments. Journal of Applied Physiology: Respiratory, Environmental and Exercise Physiology, 43(4), 678-683. doi:10.1152/jappl.1977.43.4.678

Stanley, J., Halliday, A., D’ Auria, S., Buchheit, M., \& Leicht, A.S. (2015). Effect of sauna-based heat acclimation on plasma volume and heart rate variability. European Journal of Applied Physiology, 115(4), 785-794. doi:10.1007/s00421-014-3060-1

Telford, R.D., Kovacic, J.C., Skinner, S.L., Hobbs, J.B., Hahn, A.G., \& Cunningham, R.B. (1994). Resting whole blood viscosity of elite rowers is related to performance. European Journal of Applied Physiology, 68(6), 470-476. doi:10.1007/BF00599515

Thomas, D.Q., Fernhall, B., Blanpied, P., \& Stillwell, K. (1995). Changes in running economy and mechanics during a submaximal 5-km run. The Journal of Strength and Conditioning Research, 9(3), 170-175.

Tyler, C.J., Reeve, T., Hodges, G.J., \& Cheung, S.S. (2016). The effects of heat adaptation on physiology, perception and exercise performance in the heat: A meta-analysis. Sports Medicine, 46(11), 1699-1724. PubMed ID: 27106556 doi:10.1007/s40279-016-0538-5

Wachsmuth, N.B., Volzke, C., Prommer, N., Schmidt-Trucksass, A., Frese, F., Spahl, O., . . . Schmidt, W. (2013). The effects of classic altitude training on hemoglobin mass in swimmers. European Journal of Applied Physiology, 113(5), 1199-1211. PubMed ID: 23138148 doi:10.1007/s00421-012-2536-0

White, A.C., Salgado, R.M., Astorino, T.A., Loeppky, J.A., Schneider, S.M., McCormick, J.J., . . Mermier, C.M. (2016). The effect of 10 days of heat acclimation on exercise performance in acute hypobaric hypoxia (4350 m). Temperature, 3(1), 176-185. doi:10.1080/ 23328940.2015.1072659

White, A.C., Salgado, R.M., Schneider, S., Loeppky, J.A., Astorino, T.A., \& Mermier, C.M. (2014). Does heat acclimation improve exercise capacity at altitude? A cross-tolerance model. International Journal of Sports Medicine, 35(12), 975-981. PubMed ID: 24816886

Woods, A.L., Garvican-Lewis, L.A., Rice, A., \& Thompson, K.G. (2017a). 12 days of altitude exposure at $1800 \mathrm{~m}$ does not increase resting metabolic rate in elite rowers. Applied Physiology, Nutrition, and Metabolism, 42(6), 672-676. doi:10.1139/apnm-2016-0693

Woods, A.L., Sharma, A.P., Garvican-Lewis, L.A., Saunders, P.U., Rice, A.J., \& Thompson, K.G. (2017b). Four weeks of classical altitude training increases resting metabolic rate in highly trained middledistance runners. International Journal of Sport Nutrition and Exercise Metabolism, 27(1), 83-90. doi:10.1123/ijsnem.2016-0116

Zurawlew, M.J., Walsh, N.P., Fortes, M.B., \& Potter, C. (2016). Postexercise hot water immersion induces heat acclimation and improves endurance exercise performance in the heat. Scandinavian Journal of Medicine \& Science in Sports, 26, 745-754. PubMed ID: 26661992 